\title{
Impact of CPAP on asthmatic patients with obstructive sleep apnoea
}

\author{
C. Lafond*, F. Sériès ${ }^{\#}$ and C. Lemière*
}

\begin{abstract}
The impact of continuous positive airway pressure (CPAP) treatment on the airway responsiveness of asthmatic subjects with obstructive sleep apnoea (OSA) has scarcely been studied.
\end{abstract}

A prospective study was performed comparing the changes in airway responsiveness and quality of life in stable asthmatic OSA patients, before and 6 weeks after their nocturnal CPAP treatment.

A total of 20 subjects ( 11 males and nine females) participated in the study. With the nocturnal CPAP treatment, the apnoea/hypopnoea index dropped from $48.1 \pm 23.6 \cdot h^{-1}$ to $2.6 \pm 2.5 \cdot h^{-1}$. There were no significant changes in airway responsiveness after CPAP treatment (provocative concentration causing a $20 \%$ fall in forced expiratory volume in one second (FEV 1 ; PC20 $\left.2.5 \mathrm{mg} \cdot \mathrm{mL}^{-1}(1.4-4.5)\right)$ compared with baseline $\left(P_{20} 2.2 \mathrm{mg} \cdot \mathrm{mL}^{-1}(1.3-3.5)\right)$. There was no significant change in FEV 1 either. However, the asthma quality of life of the subjects improved from $5.0 \pm 1.2$ at baseline to $5.8 \pm 0.9$ at the end of the study.

In conclusion, nocturnal continuous positive airway pressure treatment did not alter airway responsiveness or forced expiratory volume in one second in subjects with stable mild-tomoderate asthma and newly diagnosed obstructive sleep apnoea. However, nocturnal continuous positive airway pressure treatment did improve asthma quality of life.

KEYWORDS: Airway responsiveness, asthma, asthma quality of life, continuous positive airway pressure, obstructive sleep apnoea

$\mathbf{T}$ he prevalence of asthma varies widely depending on the country studied [1]. In Canada, the 1998/1999 National Population Health Survey reported a prevalence of physician-diagnosed asthma in $8.4 \%$ of the overall population [2]. The estimated prevalence of sleep nocturnal breathing disorder, defined as an apnoea/hypopnoea score $\geqslant 15 \cdot \mathrm{h}^{-1}$, is $4 \%$ in females and $9 \%$ in males [3].

Asthma and obstructive sleep apnoea (OSA) syndrome are two prevalent diseases that may coexist [4] and adversely affect health-related quality of life [5]. A high body mass index (BMI) may be an impediment in both conditions [6]. Furthermore, nasal symptoms and gastrooesophageal reflux that are often reported in OSA $[7,8]$ may exacerbate asthma $[9,10]$. In patients suffering from both conditions, nocturnal breathing disorder may be related to asthma, OSA or both [11, 12].

It is well known that continuous positive airway pressure (CPAP) is the most effective treatment for OSA [13]. It has also been reported to be

For editorial comments see page 226. effective in reducing nocturnal asthma attacks in asthmatic and apnoeic patients [14-16]. Two studies reported an improvement of airway responsiveness with $\mathrm{CPAP}$ treatment in four out of 20 apnoeic nonasthmatic patients [17] and in nine stable asthmatic nonapnoeic patients [18], respectively. However, a deleterious effect of CPAP on airway responsiveness was reported in six out of 31 OSA patients [19]. To the best of the present authors' knowledge, no study has specifically evaluated the effects of CPAP treatment on airway responsiveness of asthmatic OSA patients.

The primary aim of the present prospective study was to observe the changes in airway responsiveness in stable asthmatic OSA patients before and 6 weeks after CPAP treatment. The secondary aim was to study the impact of CPAP on quality of life specific to asthma (QOLAs) and OSA (QOLAp).

\section{MATERIAL AND METHODS \\ Study design}

Before entering the study, subjects underwent three serial methacholine inhalation challenges measured 2-3 days apart. Baseline QOLAs and
AFFILIATIONS

*Sacre-Coeur Hospital, University of Montreal, Montreal, and

\#Pneumology Research Unit, Laval Hospital Research Centre, University Institute of Cardiology and Pneumology, Laval University, Quebec City, QC, Canada.

CORRESPONDENCE

C. Lafond

5400 Boul. Gouin Ouest

Montreal

QC H4J-1C5

Canada

Fax: 15143383699

E-mail: chantal.lafond@umontreal.ca

Received:

May 042006

Accepted after revision:

September 292006

SUPPORT STATEMENT

This study was funded by the

Respiratory Health Network of FRSQ

(Fonds de Recherche en Santé du Québec).

STATEMENT OF INTEREST

None declared.

European Respiratory Journa Print ISSN 0903-1936 Online ISSN 1399-3003 
QOLAp questionnaires were completed. An atopic status was assessed using skin-prick tests to common inhalants. Gastrooesophageal symptoms and/or antireflux medication usage were assessed by way of open questionnaires.

CPAP titration was completed during a full-night polysomnography (PSG). Afterwards, CPAP treatment was started at home. After the second and fourth week of nocturnal treatment with CPAP, patients were contacted by the research nurse to verify the control of their asthma and their adaptation to the CPAP treatment.

After 6 weeks of nocturnal treatment with CPAP, objective CPAP utilisation was determined by downloading information from the CPAP unit. An in-laboratory PSG was repeated with CPAP therapy as prescribed at home. The airway responsiveness and QOLAs and QOLAp questionnaires were reassessed as performed at baseline.

\section{Subjects}

Individuals aged $\geqslant 18$ yrs with stable asthma and a new diagnosis of OSA syndrome were considered for enrolment in two centres (Sacre-Coeur Hospital, Montreal and Laval Hospital, Quebec, QC, Canada) between October 2001 and March 2005. The study was approved by the research ethics committee of each participating centre. All subjects gave their written consent.

\section{Inclusion criteria}

Asthma was defined according to the American Thoracic Society (ATS) criteria [20]. Acceptable asthma control was defined by occasional respiratory symptoms and absence of asthma exacerbation without changes in the maintenance therapy in the month preceding the study. All subjects showed airway responsiveness defined by a provocative concentration of methacholine causing a $20 \%$ fall in forced expiratory volume in one second $(\mathrm{FEV} 1) \leqslant 8 \mathrm{mg} \cdot \mathrm{mL}^{-1}(\mathrm{PC} 20)$.

All patients complained of symptoms suggestive of OSA syndrome and their apnoea/hypopnoea index (AHI) was determined during one in-laboratory PSG, the recording of which was $\geqslant 15 \cdot h^{-1}$.

\section{Exclusion criteria}

Initially, subjects were not eligible to continue the study when the variation between the lowest and the highest measure of PC20 was more than two dilutions. This assumed that their asthma was not optimally controlled or that the methacholine challenge could not be reproduced in these patients.

\section{Withdrawal criteria}

No changes in the patients' maintenance therapy for asthma were allowed during the study (which included changes in inhaled or systemic steroids, long-acting inhaled $\beta_{2}$-agonists, theophylline or leukotriene receptor antagonists) nor were the addition of steroids in nasal vaporisation and/or medication against gastro-oesophageal reflux.

Patients were withdrawn during the course of the study when compliance to their CPAP treatment was considered inadequate (average daily use $<4 \mathrm{~h} \cdot$ night $^{-1}$ ) or when asthma exacerbations unrelated to CPAP use occurred (e.g. respiratory tract infection, allergenic exposure and recurrence of smoking).

\section{Methacholine challenges}

Spirometry was performed according to the ATS standards [21]. Methacholine challenges were performed according to previously described standardised techniques [22].

\section{Sleep studies}

Initial PSG recordings consisted of in-laboratory continuous acquisition of electroencephalogram, electro-occulogram, submental electromyogram, arterial oxyhaemoglobin saturation by transcutaneous pulsed oxymetry, naso-oral airflow with thermistors, nasal pressure with nasal cannula, chest and abdominal movements by impedance plethysmography (Respitrace $^{\mathrm{TM}}$; Ambulatory Monitoring Inc., Ardsley, NY, USA), ECG and breathing sounds. Sleep position was continuously assessed by the attending technician using an infrared camera. All variables were digitally recorded (Sandman Elite ${ }^{\mathrm{TM}}$ System; Mallinckrodt, Kenilworth, NJ, USA). Sleep and respiratory variables were manually scored according to standard criteria [23].

During the CPAP titration sleep study, airflow was recorded via a pneumotachograph connected to a tightly fitting nasal CPAP mask. The titration procedure was manually completed by the attending technician, who adjusted the pressure level in order to abolish apnoeic and hypopnoeic obstructive events, snoring and inspiratory flow-limited events (effective pressure level).

\section{CPAP apparatus}

The units used at home (Fisher-Paykel, Auckland, New Zealand) were set at the effective pressure level. All the CPAP devices included a heated humidifier (ambient tracking), a ramp function and a micro-processor allowing for time of usage measurement. A nasal or a facial mask could be used.

\section{Quality-of-life questionnaires}

Validated QOLAs and QOLAp questionnaires were used [24, 25]. Scores were reported on a scale of $1-7$, with higher scores equating to better quality of life. The QOLAs questionnaire was divided into four sections: emotional function, environmental stimuli, symptoms and activity limitation.

\section{Data analysis}

All values were expressed as mean \pm SD. PC20 values were logtransformed and the mean of the three serial methacholine challenges before and after CPAP was calculated on this transformation to get one representative value before and after CPAP. Statistical results from PC20 before and after treatment were expressed with the log-transformed values as the geometric means (average of three individual geometric means before and after CPAP) and 95\% confidence interval (CI). Different correlations were examined by a Spearman rankorder test. Significance was accepted at the level of 95\%.

\section{RESULTS}

In total, 33 patients were invited to participate in the study. Six were excluded due to the high variability of their PC20 results during the screening visits. Seven were withdrawn during the study due to CPAP use $<4 \mathrm{~h} \cdot \operatorname{night}^{-1}(\mathrm{n}=3)$, an upper respiratory tract infection $(n=2)$, resumed smoking $(n=1)$ or elective orthopaedic surgery $(n=1)$. A total of 20 patients completed the study. The baseline characteristics of these 
TABLE 1 Characteristics of the subjects at baseline

\begin{tabular}{|c|c|c|}
\hline Characteristics & Completed the study & Did not complete the study \\
\hline Subjects $n$ & 20 & 13 \\
\hline Male/female & $11 / 9$ & $9 / 4$ \\
\hline BMI $\mathbf{k g} \cdot \mathrm{m}^{-2}$ & $37 \pm 9$ & $41 \pm 7$ \\
\hline \multicolumn{3}{|l|}{ Smoker status } \\
\hline Pack-yrs $^{\#}$ & $22 \pm 19$ & $36 \pm 26$ \\
\hline GERD & 6 & 2 \\
\hline Atopy & 15 & 10 \\
\hline AHI & $48 \pm 24$ & $45 \pm 31$ \\
\hline FEV $1 \%$ pred & $82 \pm 14$ & $81 \pm 20$ \\
\hline \multirow[t]{2}{*}{ Maintenance therapy for asthma } & None $^{+}$ & None $^{+}$ \\
\hline & ICS+LABA+theophylline+prednisone ${ }^{f}$ & ICS+LABA+prednisone ${ }^{f}$ \\
\hline Equivalent of fluticasone $\mathrm{mg} \cdot \mathrm{day}^{-1}$ among ICS users & $600 \pm 376$ & $500 \pm 0$ \\
\hline
\end{tabular}

patients are summarised in table 1. No differences were observed in the baseline characteristics between patients who completed the study and those who did not.

Following 6 weeks of nocturnal CPAP used on an average of $6.7 \pm 0.9 \mathrm{~h}$ at a mean pressure of $9.3 \pm 2.8 \mathrm{cmH}_{2} \mathrm{O}$, the AHI significantly dropped from $48.1 \pm 23.6 \cdot \mathrm{h}^{-1}$ at the baseline to $2.6 \pm 2.5 \cdot \mathrm{h}^{-1}$ on control PSG $(\mathrm{p}<0.001)$. All patients except one

TABLE 2 Functional and clinical characteristics of the subjects at baseline (pre-) and after 6 weeks of treatment (post-) with continuous positive airway pressure (CPAP)

\begin{tabular}{lcc} 
& Pre-CPAP & Post-CPAP \\
\hline FEV 1 \% pred & $82.2 \pm 13.6$ & $80.4 \pm 13.6$ \\
FEV $_{1} / \mathbf{F V C} \%$ & $77.3 \pm 8.3$ & $76.3 \pm 10.1$ \\
PC $\mathbf{2 0} \mathbf{~ m g} \cdot \mathbf{m L}^{-1}$ & $2.2(1.3-3.5)$ & $2.5(1.4-4.5)$ \\
AHI & $48.1 \pm 23.6$ & $2.6 \pm 2.5^{\star \star *}$ \\
QOLAs & $5.0 \pm 1.2$ & $5.8 \pm 0.9^{\star \star \star}$ \\
QOLAp & $4.1 \pm 1.4$ & $6.0 \pm 1.0^{\star \star *}$ \\
\hline
\end{tabular}

Data are presented as mean \pm SD or geometric means $(95 \%$ confidence interval), i.e. average of three individual geometric means before and after CPAP. FEV1: forced expiratory volume in one second; \% pred: \% predicted; FVC: forced vital capacity; $\mathrm{PC}_{20}$ : provocative methacholine concentration causing a $20 \%$ fall in FEV1; $\mathrm{AHI}$ : apnoea/hypopnoea index; QOLAs: quality of life specific to asthma; QOLAp: quality of life specific to obstructive sleep apnoea. ${ }^{* \star *}: p \leqslant 0.001$. used CPAP with a nasal interface. The clinical and functional characteristics related to OSA and asthma before and 6 weeks after the CPAP treatment are summarised in table 2.

No significant change in airway responsiveness before (PC20 (95\% CI) $\left.2.2 \mathrm{mg} \cdot \mathrm{mL}^{-1}(1.3-3.5)\right)$ and after 6 weeks of CPAP (PC20 $2.5 \mathrm{mg} \cdot \mathrm{mL}^{-1}(1.4-4.5) ; \mathrm{p}=0.3$; fig. 1a) was found. In three patients, a reduction of airway responsiveness was noticed after 6 weeks of CPAP, as reflected by a two-fold increase in $\mathrm{PC} 20$. Compared with the other patients, no differences were found in their age, effective CPAP pressure, CPAP compliance, BMI, AHI, gastric reflux, atopy or quality-of-life scores. However, their baseline $\mathrm{PC}_{20}$ was higher $\left(7.3 \mathrm{mg} \cdot \mathrm{mL}^{-1}\right)$ than the subjects who did not have any change in airway responsiveness $\left(1.7 \mathrm{mg} \cdot \mathrm{mL}^{-1} ; \mathrm{p}=0.02\right)$. There were no significant changes in the mean FEV1 before $(82.2 \pm 13.6 \%$ predicted) and after 6 weeks of CPAP $(80.4 \pm 13.6 \%$ pred $)$. The QOLAp statistically and clinically improved from $4.1 \pm 1.4$ at baseline to $6.0 \pm 1.0$ at the end of the study $(p<0.001)$. The QOLAs also improved statistically and clinically from $5.0 \pm 1.2$ at baseline to $5.8 \pm 0.9$ at the end of the study ( $p=0.001$; fig. $1 b)$. Clinical improvement for each QOL questionnaire is established by a score increase $\geqslant 0.5$. The QOLAs at baseline were inversely correlated with the patient's BMI (rho=-0.5, $\mathrm{p}=0.02$ ). Following the CPAP treatment, an improvement in QOLAs was positively correlated with the BMI (rho= $=0.5, \mathrm{p}=0.03)$ and the AHI at baseline $(\mathrm{rho}=0.5, \mathrm{p}=0.03)$.

There was no correlation between the BMI and the baseline AHI, or between BMI and baseline PC20. Furthermore, following the CPAP therapy, no relationship was observed between the changes in QOLAs and QOLAp as well as 

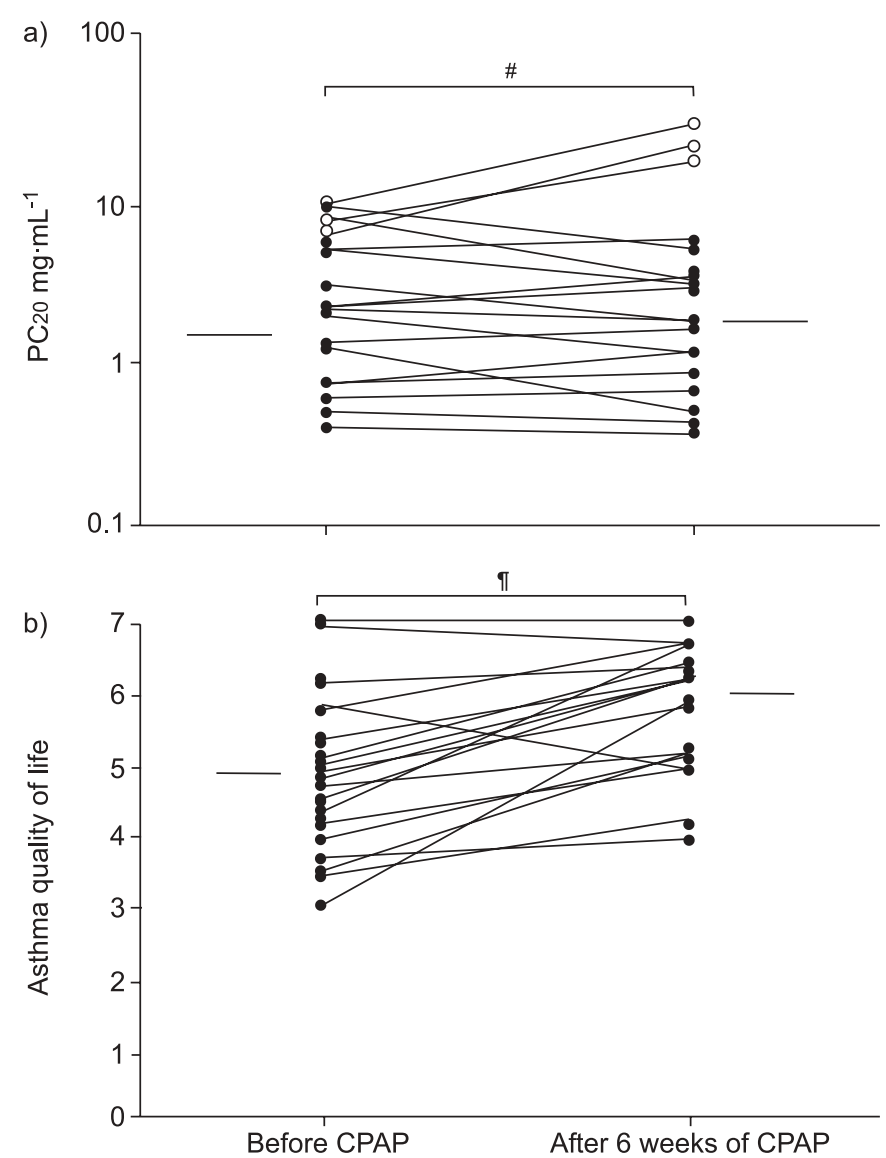

FIGURE 1. a) Changes in provocative concentration causing a $20 \%$ fall in forced expiratory volume in one second (PC20) after 6 weeks of treatment with continuous positive airway pressure (CPAP). PC20 is calculated as the geometric mean of the three serial methacholine challenges performed. $\bigcirc$ : patients with more than a two-fold increase in methacholine dilutions. b) Changes in asthma quality of life after 6 weeks of treatment with CPAP. Horizontal bars represent the mean. \#: $p=0.3^{\bullet}: p=0.001$.

between the changes in QOLAs and PC20. Following CPAP use, the BMI was correlated with the improvement of the emotional (rho=0.5, $\mathrm{p}=0.02)$ and the environmental $(\mathrm{rho}=0.5$, $\mathrm{p}=0.01$ ) domains of QOLAs. The AHI at baseline was correlated with the improvement of the symptomatic (rho=0.6, $\mathrm{p}=0.01)$, the emotional (rho=0.6, $\mathrm{p}=0.01$ ) and the environmental (rho $=0.5, \mathrm{p}=0.05)$ domains of QOLAs.

\section{DISCUSSION}

It was found that nocturnal CPAP treatment used with a heated humidifier in patients with stable asthma and newly diagnosed OSA did not modify the respiratory functional parameters, such as PC20 or FEV1. Nevertheless, the CPAP treatment improved the QOLAs. This improvement was greater in obese patients and in patients with a high AHI at baseline.

The present authors decided to enrol only stable asthmatic subjects in order to avoid potential variations in airway responsiveness related to poorly controlled asthma. Indeed, it must be remembered that the primary aim of the present study was to assess the effect of CPAP on airway responsiveness and not the control of asthma.

A total of 20 subjects may appear to be quite a small sample size, but the present authors feel that it was enough to allow detection of a clinically significant change in PC20 with greater than two-fold dilutions after CPAP use to a $99 \%$ power, with an $\alpha$-error of $5 \%$. Therefore, it is believed that should a major effect of CPAP on airway responsiveness occur, the present study would have been able to detect it.

The number of patients excluded due to insufficient use of nocturnal CPAP (three out of 23) is less than the CPAP dropout rate reported among OSA patients, since the acceptance rate of CPAP treatment among OSA patients, at large, is considered to be $\sim 70-80 \%$ [26]. It is important to notice that patients had a heated humidifier integrated into their CPAP unit, thus preventing the effects of nasopharyngeal congestion in all but one subject.

An important variability in PC20 (more than two methacholine dilutions) was found in six patients at baseline in spite of a clinically adequate control of asthma. These patients were excluded from the study. This exclusion criterion may explain the discrepancy between the present results and those from other studies, which found an improvement in PC20 after CPAP treatment $[17,18]$. In those studies, PC20 was measured on one occasion before and one after CPAP treatment. Therefore, a spontaneous PC20 variability may have occurred, which could be unrelated to CPAP treatment.

The lack of a control group comprising stable asthmatic patients without OSA prevents the present authors from concluding with certainty that the improvement of QOLAs following CPAP utilisation is specifically related to CPAP treatment. Indeed, this improvement may be due to other factors, such as a placebo effect of CPAP or improvement of adherence to asthma treatment during the study. The lack of correlation between the changes in QOLAs and QOLAp suggests that the improvement in QOLAs cannot be explained by an overall feeling of well-being consecutive to sleep normalisation following OSA treatment with CPAP. The interdependence of the questionnaires should not be completely excluded and should be addressed by experts in a future study. In a future larger study, additional analysis could possibly and more accurately determine whether BMI and AHI are independent contributors to QOLAs and its improvement with CPAP treatment.

Further randomised controlled studies including moderate-tosevere asthmatic patients with and without obstructive sleep apnoea need to be conducted in order to assess the impact of continuous positive airway pressure on asthma quality of life and its control.

\section{REFERENCES}

1 Janson C, Anto J, Burney P, et al. The European Community Respiratory Health Survey: what are the main results so far? European Community Respiratory Health Survey II. Eur Respir J 2001; 18: 598-611.

2 Health Canada. Respiratory Disease in Canada. Ottawa, Canada Lung Association, 2001. 
3 Young T, Palta M, Dempsey J, Skatrud J, Weber S, Badr S. The occurrence of sleep-disordered breathing among middle-aged adults. $N$ Eng J Med 1993; 328: 1230-1235.

4 Larsson LG, Lindberg A, Franklin KA, Lundbäck B. Symptoms related to obstructive sleep apnoea are common in subjects with asthma, chronic bronchitis and rhinitis in a general population. Respir Med 2001; 95: 423-429.

5 Ekici A, Ekici M, Kurtipek E, et al. Association of asthmarelated symptons with snoring and apnea and effect on health-related quality of life. Chest 2005; 128: 3358-3363.

6 Jubber AS. Respiratory complications of obesity. Int J Clin Pract 2004; 58: 573-580.

7 Young T, Finn L, Kim H. Nasal obstruction as a risk factor for sleep-disordered breathing. The University of Wisconsin Sleep and Respiratory Research Group. J Allergy Clin Immunol 1997; 99: 757S-762S.

8 Demeter P, Pap A. The relationship between gastroesophageal reflux disease and obstructive sleep apnea. $J$ Gastroenterol 2004; 39: 815-820.

9 Togias A. Rhinitis and asthma: evidence for respiratory system integration. J Allergy Clin Immunol 2003; 111: 1171-1183.

10 Cibella F, Cuttitta G. Nocturnal asthma and gastroesophageal reflux. Am J Med 2001; 111: 31S-36S.

11 Thomas PS, Geddes DM, Barnes PJ. Pseudo-steroid resistant asthma. Thorax 1999; 54: 352-356.

12 Yigla M, Tov N, Solomonov A, Rubin AH, Harlev D. Difficult-to-control asthma and obstructive sleep apnea. $J$ Asthma 2003; 40: 865-871.

13 Hoffstein V, Viner S, Mateika S, Conway J. Treatment of obstructive sleep apnea with nasal continuous positive airway pressure. Patient compliance, perception of benefits, and side effects. Am Rev Respir Dis 1992; 145: 841-845.

14 Guilleminault C, Quera-Salva MA, Powell N, et al. Nocturnal asthma: snoring, small pharynx and nasal CPAP. Eur Respir J 1988; 1: 902-907.

15 Chan CS, Woolcock AJ, Sullivan CE. Nocturnal asthma: role of snoring and obstructive sleep apnea. Am Rev Respir Dis 1988; 137: 1502-1504.
16 Ciftci TU, Ciftci B, Guven SF, Kokturk O, Turktas H. Effect of nasal continuous positive airway pressure in uncontrolled nocturnal asthmatic patients with obstructive sleep apnea syndrome. Respir Med 2005; 99: 529-534.

17 Lin CC, Lin CY. Obstructive sleep apnea syndrome and bronchial hyperreactivity. Lung 1995; 173: 117-126.

18 Lin $\mathrm{HC}$, Wang $\mathrm{CH}$, Yang $\mathrm{CT}$, et al. Effect of nasal continuous positive airway pressure on methacholineinduced bronchosconstriction. Respir Med 1995; 89: 121-128.

19 Wenzel G, Schonhofer B, Wenzel M, Kohler D. Bronchial hyperractivity and nCPAP therapy. Pneumologie 1997; 51: Suppl. 3, 770S-772S.

20 American Thoracic Society. Standards for the diagnosis of patients with chronic obstructive pulmonary disease (COPD) and asthma. Am Rev Respir Dis 1987; 136: 225-244.

21 American Thoracic Society. Standardization of spirometry, 1994 Update. Am J Respir Crit Care Med 1995; 152: 11071136.

22 Juniper EF, Cockcroft DW, Hargreave FE. Histamine and methacholine inhalation tests. 2nd Edn. Lund, Canadian Thoracic Society and Astra Draco AB, 1994.

23 An American Academy of Sleep Medicine Task Force. Sleep-related breathing disorders in adults: recommendations for syndrome definition and measurement techniques in clinical research. Sleep 1999; 22: 667-689.

24 Juniper EF, Guyatt GH, Epstein RS, Ferrie PJ, Jaeschke R, Hiller TK. Evaluation of impairment of health related quality of life in asthma: development of a questionnaire for use in clinical trials. Thorax 1992; 47: 76-83.

25 Lacasse Y, Bureau MP, Sériès F. A new standardized and self-administered quality of life questionnaire specific to obstructive sleep apnoea. Thorax 2004; 59: 494-499.

26 Collard P, Pieters T, Aubert G, Delguste P, Rodenstein DO. Compliance with nasal CPAP in obstructive sleep apnea patients. Sleep Med Rev 1997; 1: 33-44. 